\title{
Towards Compatibility between Ruthenium Sensitizers and Cobalt Electrolytes in Dye-Sensitized Solar Cells**
}

\author{
Lauren E. Polander, Aswani Yella, Basile F. E. Curchod, Negar Ashari Astani, Joël Teuscher, \\ Rosario Scopelliti, Peng Gao, Simon Mathew, Jacques-E. Moser, Ivano Tavernelli, \\ Ursula Rothlisberger, Michael Grätzel, Md. Khaja Nazeeruddin, and Julien Frey*
}

Dye-sensitized solar cells (DSCs) ${ }^{[1]}$ are low-cost alternatives to conventional silicon technologies for solar energy conversion. A typical DSC is composed of a chromophore that is anchored to a mesostructured anode of anatase titania $\left(\mathrm{TiO}_{2}\right)$. Upon absorption of photons, electrons are injected from the excited state of the dye into the $\mathrm{TiO}_{2}$ conduction band. Subsequently, the ground state form of the sensitizer is regenerated by reductive electron transfer from the electrolyte. The electrons injected into the semiconductor flow towards the counter electrode where the redox mediator is in turn reduced. ${ }^{[2]}$ Under simulated AM $1.5 \mathrm{G}$ illumination $\left(100 \mathrm{~mW} \mathrm{~cm}^{-2}\right)$, the power conversion efficiency of a cell $(\eta)$ is defined as the product of the generated photocurrent density $\left(J_{\mathrm{SC}}\right)$, the open-circuit photovoltage $\left(V_{\mathrm{OC}}\right),{ }^{[3]}$ and the fill factor (FF), as follows: $\eta=J_{\mathrm{SC}} V_{\mathrm{OC}} \mathrm{FF}^{[4]}$

In addition to their long-term stability, sensitizers of the $\left[\mathrm{Ru}\left(2,2^{\prime} \text {-bipyridine }\right)_{2}(\mathrm{NCS})_{2}\right]$ type have attained power conversion efficiencies of up to $12 \%$ with iodine electrolytes. ${ }^{[5-9]}$ The recent surge of organic dyes to this level of performance can be largely explained by the development of alternative redox mediators, in particular cobalt(II/III) complexes. ${ }^{[10]}$ In

[*] Dr. L. E. Polander, Dr. A. Yella, Dr. J. Teuscher, R. Scopelliti, Dr. P. Gao, Dr. S. Mathew, Prof. M. Grätzel, Dr. M. K. Nazeeruddin, Dr. J. Frey

Laboratory of Photonics and Interfaces, Institute of Chemical

Science and Engineering, École Polytechnique Fédérale

de Lausanne, 1015 Lausanne (Switzerland)

E-mail: julien.frey@gmail.com

B. F. E. Curchod, N. Ashari Astani, Dr. I. Tavernelli,

Prof. U. Rothlisberger

Laboratory of Computational Chemistry and Biochemistry, Institute of Chemical Science and Engineering, École Polytechnique Fédérale de Lausanne, 1015 Lausanne (Switzerland)

Prof. J.-E. Moser

Group for Photochemical Dynamics, Institute of Chemical Science and Engineering, École Polytechnique Fédérale de Lausanne 1015 Lausanne (Switzerland)

[**; We acknowledge financial support for this work from Solvay SA and the European Community's Seventh Framework Programme (FP7/ 2007-2013) under grant agreement no. 281063 of the Powerweave project. J.T. thanks the Swiss National Science Foundation for financial support (200020_143908). Support from the Swiss National Science Foundation (200020-130082) and the NCCRMUST interdisciplinary research program is also gratefully acknowledged. J.F. is grateful to Dr. E. Baranoff (University of Birmingham) for his invaluable mentoring.

Supporting information for this article is available on the WWWW under http://dx.doi.org/10.1002/anie.201304608. contrast to the iodide/triiodide couple $\left(\mathrm{I}^{-} / \mathrm{I}_{3}{ }^{-}\right)$, the electrochemical potential of these species can be adjusted through substitution and/or the modification of the ligand skeleton. ${ }^{[11-15]}$ This tuning minimizes energy losses in the device by optimizing the driving force for regeneration, which allows for considerable improvement of the open-circuit voltage relative to iodine electrolytes.

Current ruthenium(II) sensitizers are not designed to perform with cobalt electrolytes. Among the few examples reported in the literature ${ }^{[11,16-20]}$ only limited performances have been achieved. The highest performing dye (Z907) yields efficiencies of up to $6.5 \%$ with cobalt ${ }^{[18]}$ vs. $8.5 \%$ with iodine ${ }^{[21]}$ unless the coadsorbent is specifically engineered. ${ }^{[22]}$ Molecular dynamic simulations suggest close contact interactions between the cobalt(III) species and the anchored sensitizer(s), which causes undesired recombination of the electrons injected into the $\mathrm{TiO}_{2}$ to the redox mediator. ${ }^{[23]}$ Similar issues have been addressed for organic dyes through the addition of peripheral bulky substituents. This strategy prolongs the electron lifetime in the semiconductor by preventing the electrolyte from accessing the surface. ${ }^{[12]}$

Implementation of a similar design principle could improve compatibility between ruthenium(II) sensitizers and cobalt electrolytes. Cyclometalated tris-heteroleptic complexes have the desirable photoelectrochemical properties $^{[24]}$ to yield high-efficiency DSCs, ${ }^{[25]}$ while presenting versatility towards NCS-free sensitizers. Herein, we report a design that takes advantage of this multifunctional structure to insulate the surface from the electrolyte, tune the energy levels and the light-harvesting properties of the complex, and provide an anchor to the $\mathrm{TiO}_{2}$. Owing to this rational design, DSCs exhibiting comparable efficiencies with both cobalt and iodine redox mediators were obtained.

To improve compatibility of ruthenium(II) sensitizers with cobalt redox mediators, one could design a tris-heteroleptic complex that maintains favorable highest occupied molecular orbital (HOMO) energetics while also enabling interfacial control at the $\mathrm{TiO}_{2}$ surface. However, thus far the literature does not contain a ligand that fulfills both of these criteria. ${ }^{[26,27]}$ We found $2^{\prime}, 6^{\prime}$-dimethoxy-2,3'-bipyridine to be convenient for tuning the HOMO energy level. The alkoxy substituents are also advantageous as a substitution point to insulate the $\mathrm{TiO}_{2}$ surface by elongation of the chains. To validate this concept, both methoxy- and dodecyloxy-derivatives were synthesized. The other two ligands used to complete the coordination sphere of the ruthenium center have two functions: 2,2'-bis(5-hexylthiophen-2-yl)-2,2'-bipyr- 


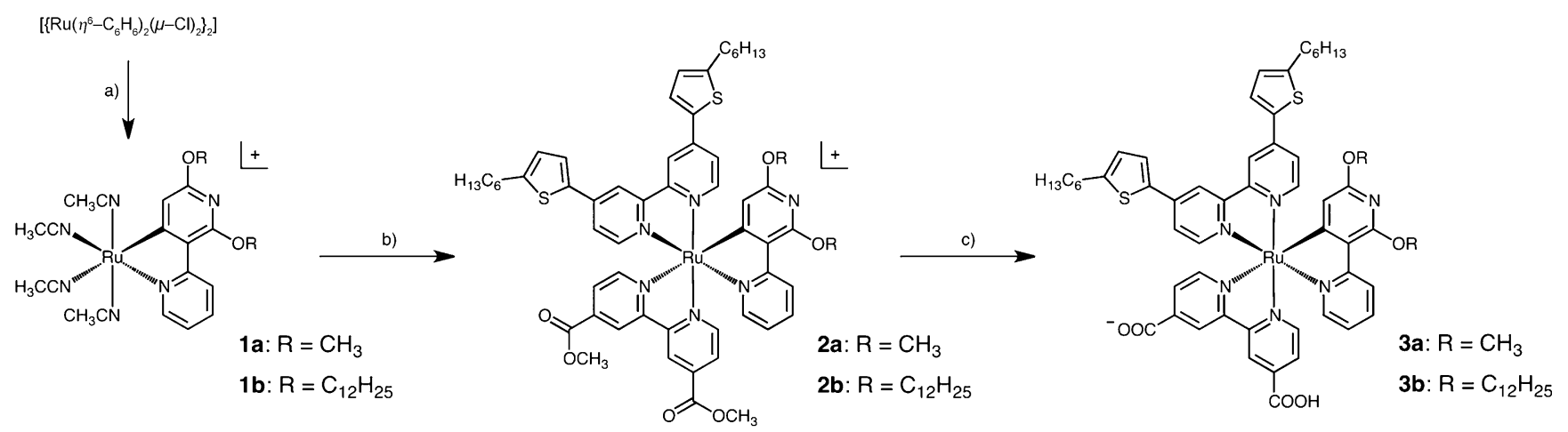

Scheme 1. Synthesis of complexes $\mathbf{3}$ a and $\mathbf{3}$ b. Charged complexes were isolated as $\mathrm{PF}_{6}{ }^{-}$salts. a) $2^{\prime}, 6^{\prime}$-dimethoxy-2, $3^{\prime}$-bipyridine or $2^{\prime}, 6^{\prime}$ bis(dodecyloxy)-2,3'-bipyridine, $\mathrm{NaOH}, \mathrm{KPF}_{6}$ in $\mathrm{MeCN}$ (1 a: 56\%, 1 b: 43\%); b) 2,2'-bis(5-hexylthiophen-2-yl)-2,2'-bipyridine, 4,4'-dimethylester-2,2'bipyridine in $\mathrm{EtOH}(2 \mathrm{a}: 48 \% ; 2 \mathrm{~b}: 45 \%)$; c) DMF, $\mathrm{H}_{2} \mathrm{O}, \mathrm{Et}_{3} \mathrm{~N}(3: 1: 1)(\mathbf{3} \mathrm{a}: 77 \% ; \mathbf{3}$ b: $95 \%)$.

idine enhances the absorptivity of the complex, compared to an unsubstituted $2,2^{\prime}$-bipyridine ligand, ${ }^{[7]}$ whereas $2,2^{\prime}$-bipyridine-4,4'-dicarboxylic acid serves as an electron-accepting ligand and anchor to the $\mathrm{TiO}_{2}$.

Complexes 1-3 were prepared by following a straightforward procedure developed by Berlinguette et al. ${ }^{[19]}$ As shown in Scheme 1, with $\left[\left\{\mathrm{Ru}\left(\mathrm{C}_{6} \mathrm{H}_{6}\right) \mathrm{Cl}_{2}\right\}_{2}\right]$ as the ruthenium source, the cyclometalating ligand is introduced first to yield precursors $\mathbf{1} \mathbf{a}$ and $\mathbf{1 b}$. The complex is subsequently reacted with stoichiometric amounts of the two different bipyridine ligands, in a one-pot procedure that gives the desired complexes, $\mathbf{2} \mathbf{a}$ or $\mathbf{2} \mathbf{b}$, in yields close to the theoretical limit. Finally, sensitizers $\mathbf{3 a}$ and $\mathbf{3 b}$ are obtained as neutral complexes after saponification. Unlike most ruthenium(II) sensitizers, which are isolated using size-exclusion chromatography, complexes 1-3 can be purified using conventional chromatography over alumina or silica and by using precipitation techniques. Details on the synthesis and characterization of these compounds are given in the Supporting Information.

Owing to their tris-heteroleptic nature, complexes $\mathbf{2}$ and $\mathbf{3}$ can potentially adopt two conformations with cyclometalation either in trans to the dicarboxy-bipyridine or in trans to the dithiophenyl-bipyridine ligand. The NMR data indicate that a single isomer is produced. To confirm the arrangement of the ligands around the metal center, single crystals of $\mathbf{2 a}$ were grown by slow diffusion of hexane into a dichloromethane solution. The crystal structure is shown in Figure 1, with selected bond lengths and angles presented in the Supporting Information, Table S2. As expected, the complex adopts a distorted octahedral geometry around the ruthenium center. The dimethoxy ester bipyridine ligand, located trans to the cyclometalated ring, experiences the electron donating character of the $\mathrm{C} 24-\mathrm{Ru}$ bond, which manifests in an elongation of the $\mathrm{Ru}-\mathrm{N} 1$ bond. The NMR analysis from which we conclude that complexes $\mathbf{2}$ and $\mathbf{3}$ adopt this same conformation (Figures S7 and S8) is consistent with the observed trans effect, as detailed in the Supporting Information. The methoxy substituents of the cyclometalated ring are arranged within the plane of the ligand to avoid lone pair interactions with the pyridyl nitrogen. At the light-harvesting

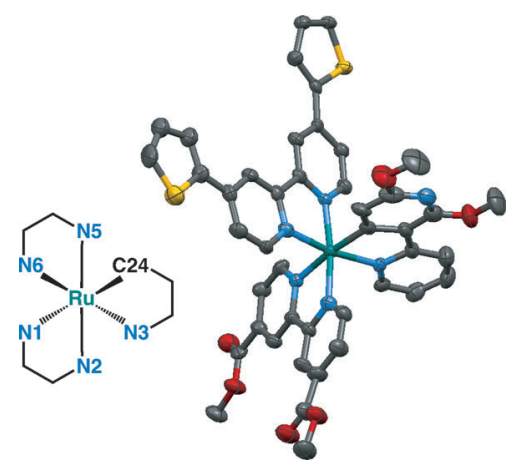

Figure 1. Crystal structure of $2 \mathrm{a} \cdot 2 \mathrm{CH}_{2} \mathrm{Cl}_{2}$. Thermal ellipsoids are drawn at the $50 \%$ probability level. The counter ion, hexyl chains, hydrogen atoms, and solvent molecules are omitted for clarity. Additional information can be found in Table S1. $\mathrm{N}$ blue, $\mathrm{O}$ red, $\mathrm{S}$ yellow, Ru turquoise.

ligand, the thiophenes lie in the 2,2'-bipyridine plane (torsions angles $<1^{\circ}$ ), thus ensuring good electronic communication.

The optical and electrochemical properties of $\mathbf{3 a}$ and $\mathbf{3 b}$ were determined in dichloromethane solution (Figure 2; see also Figures S10 and S11). Both complexes show virtually identical properties, as summarized in Table S3. The UV/Vis spectrum of $\mathbf{3 b}$ shows broad and intense absorptions below $350 \mathrm{~nm}$ that are dominated by $\pi-\pi^{*}$ transitions. At longer wavelengths, the spectrum reveals two strong bands centered
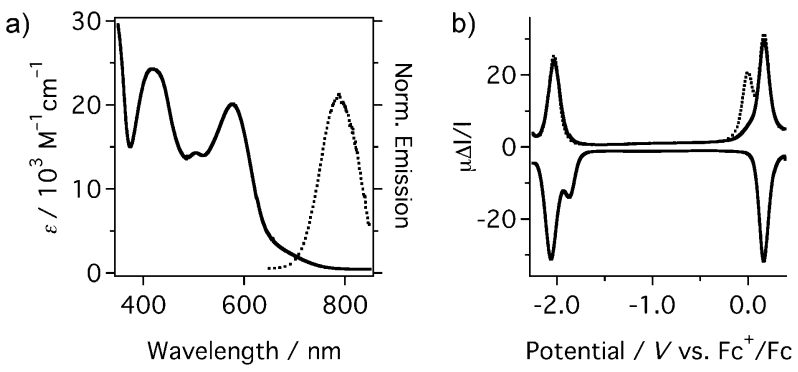

Figure 2. a) Steady-state absorption $(\longrightarrow$ ) and normalized emission spectra $\left(----, \lambda_{\text {exc }}=580 \mathrm{~nm}\right)$, and b) differential pulse voltammogram $(\longrightarrow)$ with a ferrocene internal standard (-----) in dichloromethane of 3 b. Scan rate of $100 \mathrm{mVs}^{-1}$ with $10 \mathrm{mV}$ pulses. 
at $418 \mathrm{~nm}\left(23400 \mathrm{M} \mathrm{cm}^{-1}\right)$ and $580 \mathrm{~nm}\left(19600 \mathrm{M} \mathrm{cm}^{-1}\right)$, which are characteristic of metal-to-ligand charge-transfer transitions. These assignments are further supported by timedependent density functional theory calculations for $\mathbf{3 a}$ (LRTDDFT/M06; Figures S12-S21). Full details on the quantum chemical calculations can be found in the Supporting Information.

Furthermore, the energy levels of complexes $\mathbf{3 a}$ and $\mathbf{3 b}$ are adequately poised for use in DSCs. The differential pulse voltammogram of complex $\mathbf{3 b}$ exhibits quasi-reversible oneelectron oxidation at $+0.86 \mathrm{~V}\left(E_{\mathrm{HOMO}}=-4.91 \mathrm{eV}\right)$ and oneelectron reduction at $-1.35 \mathrm{~V}$ vs. NHE. ${ }^{[28]}$ The anodic peak potential is ascribed to oxidation of the metal center to ruthenium(III), whereas the cathodic peak is assigned to a ligand-centered reduction. According to (U)DFT/M06 calculations, the vertical ionization energy of $\mathbf{3 a}$ is calculated at $5.04 \mathrm{eV}$, whereas the adiabatic ionization energy lies at $4.96 \mathrm{eV}$. Both values are in good agreement with the estimated HOMO energy and corroborate the oxidation of the ruthenium center. ${ }^{[29]}$ As observed in Figure S13, the spin density of the geometry optimized $\mathbf{3} \mathbf{a}^{++}$appears only slightly delocalized over the cyclometalated pyridine.

These $E_{\mathrm{S}+/ \mathrm{S}}$ values allow regeneration of $\mathbf{3} \mathbf{a}^{\cdot+}$ and $\mathbf{3} \mathbf{b}^{++}$ from iodine $\left(E^{0}=+0.35 \mathrm{~V}\right.$ vs. $\left.\mathrm{NHE}\right)$, as well as a variety of cobalt-based electrolytes with more positive electrochemical potentials. ${ }^{[13]}$ In this study, a tris(1,10-phenanthroline) cobalt(II/III) $\left(\left[\mathrm{Co}^{\mathrm{II} / \mathrm{III}}(\text { phen })_{3}\right]^{2 / 3+}, E^{0}=+0.62 \mathrm{~V}\right.$ vs. NHE) electrolyte is chosen to maximize the $V_{\mathrm{OC}}$ while maintaining sufficient driving force for regeneration. The excited state oxidation potential of the dyes $\left(E_{\mathrm{S}+/ \mathrm{S}^{*}}\right)$ is estimated using the zero-zero transition energy $\left(E_{0-0}\right)$ measured at the intersection of the absorption and normalized emission spectra. The $E_{\mathrm{S}+/ S^{*}}$ values obtained for $\mathbf{3 a}$ and $\mathbf{3 b}$ (ca. $-0.90 \mathrm{~V}$ vs. NHE) provide a priori ample driving force for electron injection into the $\mathrm{TiO}_{2}$ conduction band $\left(E_{\mathrm{C}}=\right.$ ca. $-0.5 \mathrm{~V}$ vs. NHE) ${ }^{[30]}$

Provided that electron injection is not an issue, the efficiency of $\mathrm{TiO}_{2}$ films sensitized with $\mathbf{3} \mathbf{a}$ and $\mathbf{3} \mathbf{b}$ depends on two main charge-transfer reactions: 1) back-recombination, which corresponds to electron transfer from the electron in the $\mathrm{TiO}_{2}$ to the oxidized dye, and 2) dye-regeneration, which corresponds to reductive electron transfer from the electrolyte to the oxidized sensitizer. Their respective time constants $\left(\tau_{\text {rec }}\right.$ and $\left.\tau_{\text {reg }}\right)$ can be quantified using transient absorption (TA) decay measurements. The oxidized forms of the dyes have absorption spectra that differ sharply from their neutral counterparts (Figure $3 \mathrm{a}, \mathrm{b}$ ). Following excitation at $470 \mathrm{~nm}$, the photoinduced absorption (PIA) signal that appears at $740 \mathrm{~nm}$ is characteristic of the formation of a ruthenium(III) species, ${ }^{[31]}$ whose TA decay is used to derive the corresponding time constants. The decays were fitted with a single exponential component $\Delta A(t) \propto A_{0} \exp [-(t / \tau)]$, where $A_{0}$ is the pre-exponential factor and $\tau$ is the characteristic time constant. ${ }^{[32]}$ The fits are represented as solid lines on Figure $3 \mathrm{c}, \mathrm{d}$. With an inert electrolyte, $\tau_{\text {rec }}$ was estimated at 280 and $373 \mu$ s for $\mathbf{3 a}$ and $\mathbf{3 b}$, respectively. In contrast, the presence of $\left[\mathrm{Co}^{\mathrm{II} / \mathrm{III}}(\text { phen })_{3}\right]^{2 / 3+}$ gives rise to accelerated TA decays, with $\tau_{\text {reg }}$ values of $9.7 \mu$ s and $17 \mu$ s for $\mathbf{3 a}$ and $\mathbf{3 b}$, respectively. These $\tau_{\text {rec }}$ and $\tau_{\text {reg }}$ constants indicate nearly quantitative regeneration quantum yields, $\Phi_{\text {reg }}=k_{\text {reg }}$ l
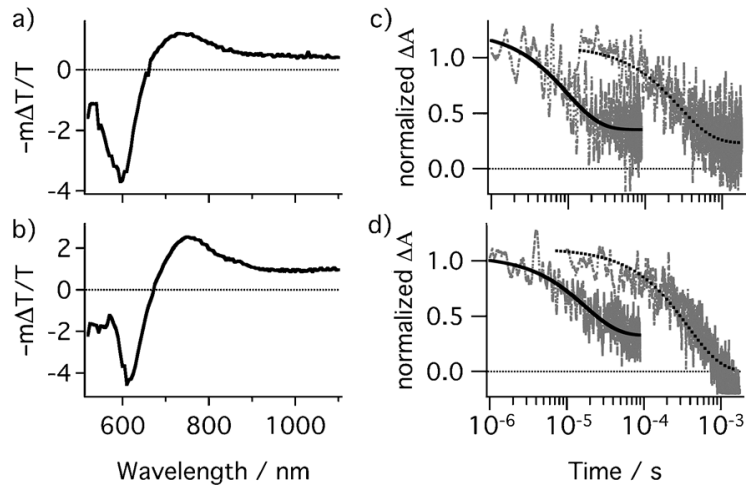

Figure 3. a,b) PIA spectra after $470 \mathrm{~nm}$ excitation, and (c,d) TA decay traces following excitation at $520 \mathrm{~nm}$ (probe at $750 \mathrm{~nm}$ ) of $8.0 \mu \mathrm{m}$ thick $\mathrm{TiO}_{2}$ films coated with $\mathbf{3} \mathbf{a}(\mathrm{a}, \mathrm{c})$ and $\mathbf{3} \mathbf{b}(\mathrm{b}, \mathrm{d})$, respectively.

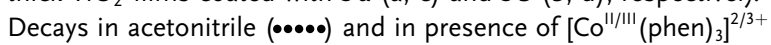
electrolyte $(\longrightarrow$ ) were fitted with a single exponential component $\Delta A(t) \propto A_{0} \exp [-(t / \tau)] .7 \mathrm{~ns}$ (fwhm) laser pulse of $50 \mu \mathrm{J} \mathrm{cm}^{-2}$.

$\left(k_{\text {reg }}+k_{\text {rec }}\right)=96 \%$ (where $\left.k_{\mathrm{i}}=1 / \tau_{\mathrm{i}}\right)$, which is paramount for efficient DSCs.

The incident photon-to-current efficiency (IPCE) spectra using a $\left[\mathrm{Co}^{\mathrm{II} / I I I}(\text { phen })_{3}\right]^{2 / 3+}$ electrolyte are shown in Figure $4 \mathrm{a}$. Complex $\mathbf{3 b}$ was also investigated using $\mathrm{I}^{-} / \mathrm{I}_{3}{ }^{-}$for comparison purposes. The three IPCEs have a similar shape in the range a)

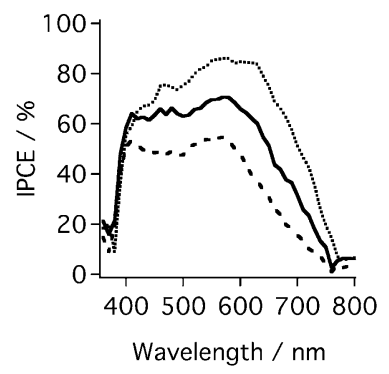

b)

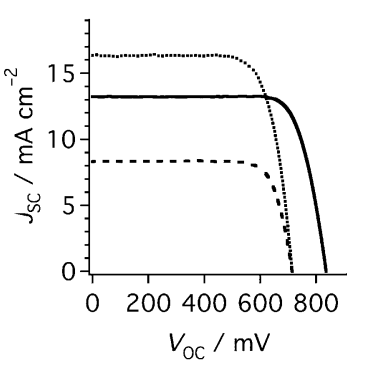

Figure 4. a) Photocurrent action spectra in mesoscopic solar cells, and b) $J-V$ characteristics measured under simulated AM 1.5 G full sun illumination $\left(100 \mathrm{~mW} \mathrm{~cm}^{-2}\right)$ for devices employing $\mathbf{3} \mathbf{a}$ and $\mathbf{3} \mathbf{b}$. Film thickness: $(4.0+4.0) \mu \mathrm{m}$. Cobalt electrolyte: $0.25 \mathrm{M}\left[\mathrm{Co}(\text { phen })_{3}\right](\mathrm{TFSI})_{2}$, $0.05 \mathrm{M}\left[\mathrm{Co}(\text { phen })_{3}\right](\mathrm{TFSI})_{3}, 0.25 \mathrm{M} \mathrm{TBP}, 0.1 \mathrm{M} \mathrm{LiTFSI}$ in acetonitrile; iodine electrolyte: $1.0 \mathrm{M}$ PMII, $0.03 \mathrm{M} \mathrm{I}_{2}, 0.5 \mathrm{M}$ TBP, $0.1 \mathrm{M}$ GuNCS, 0.05 M Lil. 3 a+cobalt (----), 3 b+cobalt $(-)$, 3 b+iodine (....•). GuNCS $=$ guanidinium thiocyanate, phen $=1,10$-phenanthroline, $\mathrm{PMII}=1$-propyl-3-methylimidazolium iodide, TBP = 4-tert-butylpyridine, TFSI = trifluoromethanesulfonimide.

of 380-770 nm, but with significantly different intensities. Similar to other ruthenium(II) sensitizers, ${ }^{[18,19,22]}$ the photocurrent action spectra is limited to ca. $50 \%$ with $3 \mathbf{a}$. The presence of $\mathrm{C}_{12}$ alkoxy chains on the cyclometalated ligand results in an increase of up to $70 \%$, as exemplified by $\mathbf{3 b}$. Notably, this is lower than what can be obtained when iodine is used as redox mediator. The solar-to-electricity conversion efficiencies were evaluated by recording the $J-V$ characteristics under simulated AM $1.5 \mathrm{G}$ illumination $\left(100 \mathrm{~mW} \mathrm{~cm}^{-2}\right)$. Results are depicted in Figure $4 \mathrm{~b}$ and photovoltaic parameters are reported in Table 1 . As expected, the $J_{\mathrm{SC}}$ values follow 
Table 1: Detailed photovoltaic parameters of devices employing $\mathbf{3} \mathbf{a}$ and 3 b under simulated AM $1.5 \mathrm{G}$ illumination $\left(100 \mathrm{mWcm}^{-2}\right)$.

\begin{tabular}{llllll}
\hline Dye & Electrolyte & $J_{\text {SC }}\left[\mathrm{mAcm}^{-2}\right]$ & $V_{\text {OC }}[\mathrm{mV}]$ & FF & $\eta[\%]$ \\
\hline 3 a & cobalt & 8.3 & 714 & 0.79 & 4.7 \\
3 b & cobalt & 13.2 & 837 & 0.78 & 8.6 \\
3 b & iodine & 16.3 & 715 & 0.75 & 8.7 \\
\hline
\end{tabular}

the trend observed in IPCE intensities. The measured $V_{\mathrm{OC}}$ values show large differences between $\mathbf{3 a}$ and $\mathbf{3 b}$. The lower $V_{\mathrm{OC}}$ obtained with iodine in the case of $\mathbf{3} \mathbf{b}$ highlights the benefit of using a cobalt electrolyte.

Relative shifts in IPCE intensities and $J-V$ characteristics can be rationalized based on transient photovoltage decays and charge extraction measurements. While maintaining constant electrolyte, variations in $V_{\mathrm{OC}}$ can often be attributed to shifts in the conduction band edge of $\mathrm{TiO}_{2}{ }^{[33]}$ In the presence of $\left[\mathrm{Co}^{\mathrm{II} / \mathrm{III}}(\mathrm{phen})_{3}\right]^{2 / 3+}$, we observe negligible variation in the conduction band edge (Figure $5 \mathrm{a}$ ), which indicates
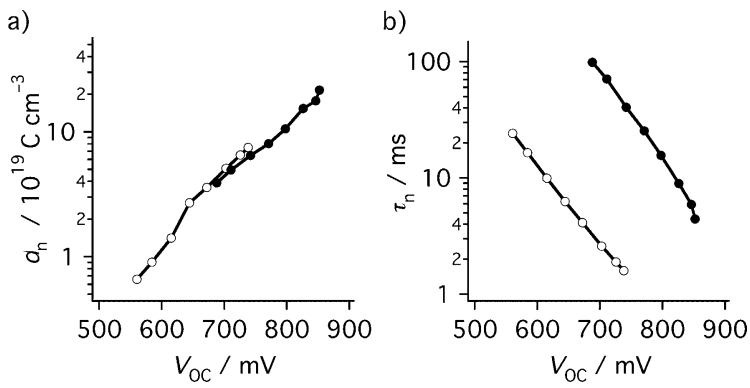

Figure 5. a) Charge density of $\mathrm{TiO}_{2}\left(d_{n}\right)$, and b) electron lifetime $\left(\tau_{n}\right)$ against the open-circuit photovoltage $\left(V_{O C}\right) \cdot \mathbf{3} \mathbf{a}+$ cobalt $(O), \mathbf{3} \mathbf{b}+$ cobalt (๑).

that the $\mathrm{TiO}_{2}$ experiences a similar dipole shift with $\mathbf{3 a}$ and 3b. Therefore, differences in $V_{\mathrm{OC}}$ can be attributed to the relative electron lifetimes in $\mathrm{TiO}_{2}\left(\tau_{\mathrm{n}}\right)$; the electron lifetime of $\mathbf{3} \mathbf{b}$ is prolonged by ca. 1.5 orders of magnitude relative to $\mathbf{3 a}$ (Figure $5 \mathrm{~b}$ ). The recombination of electrons injected into the semiconductor can occur by reductive electron transfer to the electrolyte and/or to the oxidized form of the sensitizer. Given that the time constants for recombination of injected electrons with $\mathbf{3} \mathbf{a}^{++}$and $\mathbf{3} \mathbf{b}^{++}$are similar, the presence of $\mathrm{C}_{12}$ alkoxy chains clearly insulates the $\mathrm{TiO}_{2}$ surface by preventing close proximity with the redox mediator. This effect has a major impact on both the $J_{\mathrm{SC}}$ and $V_{\mathrm{OC}}$ photovoltaic parameters, as shown in Table 1 . Overall, the $J_{\mathrm{SC}}$ and $V_{\mathrm{OC}}$ obtained for $\mathbf{3 a}\left(8.3 \mathrm{~mA} \mathrm{~cm}^{-2}\right.$ and $714 \mathrm{mV}$, respectively) contribute to a power conversion efficiency of $4.7 \%$. As a result of the increased electron lifetime, the values measured for $\mathbf{3 b}$ rise to $13.2 \mathrm{mAcm}^{-2}$ and $837 \mathrm{mV}$, respectively; DSCs with this sensitizer reach efficiencies of up to $8.6 \%$ in the presence of a cobalt electrolyte. Notably, this result closely matches that obtained with iodine $(8.7 \%)$, which has not been thus far reported for a ruthenium(II) sensitizer.

In summary, we have shown that the efficiency of cyclometalated ruthenium(II) sensitizers can be greatly improved in cobalt-based DSCs. Upon increasing the steric properties of the cyclometalating ring, notable improvements in photon-to-current conversion and $J-V$ characteristics are observed. Transient absorption decay measurements indicate that the kinetics of recombination and regeneration remain constant, despite the modifications of the sensitizers. However, through charge extraction measurements, the device efficiency is directly correlated to increased surface protection. Physical insulation of the $\mathrm{TiO}_{2}$ surface prolongs the electron lifetime by preventing abnormal recombination of injected electrons into the cobalt(III) species. This approach demonstrates a general principle that leads to unprecedented efficiency for a ruthenium(II) sensitizer used in combination with a cobalt electrolyte.

Received: May 28, 2013

Published online: July 4, 2013

Keywords: cobalt - dye-sensitized solar cells . energy conversion · ruthenium · sensitizers

[1] B. O'Regan, M. Grätzel, Nature 1991, 353, 737-740.

[2] A. Hagfeldt, G. Boschloo, L. Sun, L. Kloo, H. Pettersson, Chem. Rev. 2010, 110, 6595-6663.

[3] The $V_{\mathrm{OC}}$ is defined as the energy difference between the Fermi level $\left(E_{\mathrm{F}}\right)$ of the $\mathrm{TiO}_{2}$ and the HOMO level of the redox mediator, as follows: $V_{\mathrm{OC}}=\left(E_{\mathrm{F}}-E_{\mathrm{HOMO}}\right) / e$, where $e$ is the elementary charge.

[4] This equation is applicable under $100 \mathrm{~mW} \mathrm{~cm}^{-2}$ irradiation with $J_{\mathrm{SC}}$ in $\mathrm{mA} \mathrm{cm}^{-2}$ and $V_{\mathrm{OC}}$ in $\mathrm{V}$.

[5] M. K. Nazeeruddin, F. De Angelis, S. Fantacci, A. Selloni, G. Viscardi, P. Liska, S. Ito, B. Takeru, M. Grätzel, J. Am. Chem. Soc. 2005, 127, $16835-16847$.

[6] Y. Chiba, A. Islam, Y. Watanabe, R. Komiya, N. Koide, L. Han, Jpn. J. Appl. Phys. 2006, 45, L638-L640.

[7] F. Gao, Y. Wang, D. Shi, J. Zhang, M. Wang, X. Jing, R. Humphry-Baker, P. Wang, S. M. Zakeeruddin, M. Grätzel, J. Am. Chem. Soc. 2008, 130, 10720-10728.

[8] C.-Y. Chen, M. Wang, J.-Y. Li, N. Pootrakulchote, L. Alibabaei, C.-H. Ngoc-le, J.-D. Decoppet, J.-H. Tsai, C. Grätzel, C.-G. Wu et al., ACS Nano 2009, 3, 3103-3109.

[9] Q. Yu, Y. Wang, Z. Yi, N. Zu, J. Zhang, M. Zhang, P. Wang, ACS Nano 2010, 4, 6032-6038.

[10] A. Yella, H.-W. Lee, H. N. Tsao, C. Yi, A. K. Chandiran, M. K. Nazeeruddin, E. W.-G. Diau, C.-Y. Yeh, S. M. Zakeeruddin, M. Grätzel, Science 2011, 334, 629-634.

[11] S. A. Sapp, C. M. Elliott, C. Contado, S. Caramori, C. A. Bignozzi, J. Am. Chem. Soc. 2002, 124, 11215-11222.

[12] S. M. Feldt, E. A. Gibson, E. Gabrielsson, L. Sun, G. Boschloo, A. Hagfeldt, J. Am. Chem. Soc. 2010, 132, 16714-16724.

[13] S. M. Feldt, G. Wang, G. Boschloo, A. Hagfeldt, J. Phys. Chem. C 2011, 115, 21500-21507.

[14] J.-H. Yum, E. Baranoff, F. Kessler, T. Moehl, S. Ahmad, T. Bessho, A. Marchioro, E. Ghadiri, J.-E. Moser, C. Yi et al., Nat. Commun. 2012, 3, 631.

[15] M. K. Kashif, J. C. Axelson, N. W. Duffy, C. M. Forsyth, C. J. Chang, J. R. Long, L. Spiccia, U. Bach, J. Am. Chem. Soc. 2012, 134, 16646-16653.

[16] H. Nusbaumer, S. M. Zakeeruddin, J.-E. Moser, M. Grätzel, Chem. Eur. J. 2003, 9, 3756-3763.

[17] B. M. Klahr, T. W. Hamann, J. Phys. Chem. C 2009, 113, 1404014045 . 
[18] Y. Liu, J. R. Jennings, Y. Huang, Q. Wang, S. M. Zakeeruddin, M. Grätzel, J. Phys. Chem. C 2011, 115, 18847-18855.

[19] P. G. Bomben, T. J. Gordon, E. Schott, C. P. Berlinguette, Angew. Chem. 2011, 123, 10870-10873; Angew. Chem. Int. Ed. 2011, 50 , $10682-10685$

[20] Y. Xie, T. W. Hamann, J. Phys. Chem. Lett. 2013, 4, 328-332.

[21] S. M. Zakeeruddin, M. K. Nazeeruddin, R. Humphry-Baker, P. Péchy, P. Quagliotto, C. Barolo, G. Viscardi, M. Grätzel, Langmuir 2002, 18, $952-954$.

[22] Y. Liu, J. R. Jennings, X. Wang, Q. Wang, Phys. Chem. Chem. Phys. 2013, 15, 6170-6174.

[23] E. Mosconi, J.-H. Yum, F. Kessler, C. J. Gomez-Garcia, C. Zuccaccia, A. Cinti, M. K. Nazeeruddin, M. Grätzel, F. De Angelis, J. Am. Chem. Soc. 2012, 134, 19438-19453.

[24] P. G. Bomben, K. C. D. Robson, P. A. Sedach, C. P. Berlinguette, Inorg. Chem. 2009, 48, 9631-9643.

[25] T. Bessho, E. Yoneda, J.-H. Yum, M. Guglielmi, I. Tavernelli, H. Imai, U. Rothlisberger, M. K. Nazeeruddin, M. Grätzel, J. Am. Chem. Soc. 2009, 131, 5930-5934.
[26] P. G. Bomben, B. D. Koivisto, C. P. Berlinguette, Inorg. Chem. 2010, 49, 4960-4971.

[27] P. G. Bomben, K. D. Thériault, C. P. Berlinguette, Eur. J. Inorg. Chem. 2011, 1806-1814.

[28] N. G. Connelly, W. E. Geiger, Chem. Rev. 1996, 96, 877-910.

[29] The vertical ionization corresponds to the energy difference between the cationic and the neutral species at the molecular geometry of the neutral compound; the adiabatic ionization energy corresponds to the energy difference between the optimized cationic and optimized neutral species.

[30] A. Hagfeldt, M. Grätzel, Chem. Rev. 1995, 95, 49-68.

[31] S. Ardo, G. J. Meyer, Chem. Soc. Rev. 2009, 38, 115-164.

[32] A. Y. Anderson, P. R. F. Barnes, J. R. Durrant, B. C. O'Regan, J. Phys. Chem. C 2011, 115, 2439-2447, and references therein.

[33] P. R. F. Barnes, K. Miettunen, X. Li, A. Y. Anderson, T. Bessho, M. Grätzel, B. C. O’Regan, Adv. Mater. 2013, 25, 1881-1922. 